\title{
Selected Topics on Socio-technical Perspective in Information Systems: Editorial Introduction to Issue 22 of CSIMQ
}

\author{
Peter Bednar ${ }^{1,2 \star}$ and Alexander Nolte ${ }^{3,4}$ \\ ${ }^{1}$ School of Computing, University of Portsmouth, Buckingham Building, Lion Terrace, Portsmouth PO1 3HE, UK \\ ${ }^{2}$ Department of Informatics, Lund University, Ole Römers väg 6, 22363 Lund, Sweden \\ ${ }^{3}$ Institute of Computer Science, University of Tartu, Narva maantee 18, 51009 Tartu, Estonia \\ ${ }^{4}$ Institute for Software Research, Carnegie Mellon University, Pittsburgh, PA, USA \\ peter.bednar@port.ac.uk, alexander.nolte@ut.ee
}

This thematic issue of the Complex Systems Informatics and Modeling Quarterly (CSIMQ) journal is dedicated to fostering a socio-technical perspective in the Information Systems (IS) field. The contemporary perspective has developed a lot over the years and the socio-technical agenda continues to be relevant as recognized by Berniker [1] in his discussion on the future of socio-technical systems theory and practice and in the discussions by Sarker et al. [2], Pasmore et al. [3], and Ceschin and Gaziulusoy [4].

This issue contains a selection of extended papers presented at STPIS'19 - 5th International Workshop on Socio-Technical Perspective in IS Development held on June 10, 2019 in Stockholm, Sweden in conjunction with the 27th European Conference on Information Systems (ECIS) [5]-[9]. The workshop featured presentations of 13 papers and 3 posters and was attended by more than 30 participants from 8 different countries (Sweden, Norway, Finland, UK, Germany, Italy, Switzerland, and US). Four of the presented papers were extended for publication in this thematic issue. The articles presented in this thematic issue contain at least 30\% new material compared to the papers initially submitted for the workshop. The last included article was submitted as a regular contribution to the CSIMQ journal and was selected to be included into this thematic issue because of its close connection to the topic of socio-technical systems. All articles went through two rounds of reviews to ensure the quality of the articles published in this issue. STPIS articles cover both theoretical and practical aspects of using a socio-technical perspective in IS, which is reflected in the current issue that contains both theoretically and practically oriented articles.

The first article "Ethnographically Derived Socio-technical Analysis for Information System Support in Intensive Home Care" co-authored by Markus Jelonek, Thomas Herrmann, Nina Altmann, and Michael Ksoll takes a practical perspective. In this article the authors report on results from an empirical study of caregivers in a intensive care home thus contributing to the health care information system literature from a socio-technical perspective.

The second and third article take a more theoretically focused perspective on socio-technical systems. The authors of second article "Using Enterprise Models to Explain and Discuss

\footnotetext{
* Corresponding author

(C) 2020 Peter Bednar et al. This is an open access article licensed under the Creative Commons Attribution License (http://creativecommons.org/licenses/by/4.0).

Reference: P. Bednar and A. Nolte, "Selected Topics on Socio-technical Perspective in Information Systems: Editorial Introduction to Issue 22 of CSIMQ," Complex Systems Informatics and Modeling Quarterly, CSIMQ, no. 22, pp. I-II, 2020. Available: https://doi.org/10.7250/csimq.2020-22.00
}

Additional information. Author ORCID iD: P. Bednar - https://orcid.org/0000-0002-3631-2626 and A. Nolte https://orcid.org/0000-0003-1255-824X. PII S225599222000125X. Received: 23 April 2020. Available online: 30 April 2020. 
Autopoiesis and Homeostasis in Socio-technical Systems" Ilia Bider, Gil Regev, and Erik Perjons apply two theoretical concepts from biology - namely autopoiesis and homeostasis - to socio-technical systems by proposing a expansion to the Fractal Enterprise Model (FEM). The third article "Reviving the Individual in Socio-technical Systems Thinking" authored by Lars Taxén illustrates an approach for socio-technical systems thinking which is centered on the perspective of individuals. This approach is different to common socio-technical approaches which typically focus on the interconnection between technical and social systems.

The fourth and fifth article propose methodological additions to the common canon of socio-technical design approaches. In the fourth article "Usability as Speculum Mundi: A Core Concept in Socio-technical Systems Development" the authors Mikko Rajanen and Dorina Rajanen propose a concept to use usability as lens for analyzing socio-technical systems. The fifth and final article in this issue entitled "Just Finished a Cycle of a Design Science Research Project: What's Next?" was co-authored by Ilia Bider, Erik Perjons and Paul Johannesson. In this article the authors propose a classification for design science (DS) cycles and provide guidelines for how to choose the next cycle based on a study of two design science projects.

We are grateful to everyone who has contributed to the workshop and to this thematic issue, including authors and reviewers. We are also thankful to the managing editor of the CSIMQ journal Marite Kirikova for her support throughout the whole process of preparation of this issue.

\section{References}

[1] E. Berniker, "The Future of Sociotechnical Systems Theory and Practice: The Challenges for Information System Design,” International Journal of Systems and Society, vol. 3, no. 1, 2016.

[2] S. Sarker, S. Chatterjee, X. Xiao, and A. Elbanna, "The Sociotechnical Axis of Cohesion for the IS Discipline: Its Historical Legacy and its Continued Relevance," MIS Quarterly, vol. 43, no. 3, pp. 695-719, 2019. Available: https://doi.org/10.25300/MISQ/2019/13747

[3] W. Pasmore, S. Winby, S. Albers-Mohrman, and R. Vanasse, "Reflections: Sociotechnical Systems Design and Organization Change," Journal of Change Management, vol. 19, no. 2, pp. 67-85, 2019. Available: https://doi.org/10.1080/14697017.2018.1553761

[4] F. Ceschin and I. Gaziulusoy, Design for Sustainability: A Multi- level Framework from Products to Socio-technical Systems, Routledge, 2020. Available: https://doi.org/10.4324/9780429456510

[5] S. Kowalski, P. Bednar, A. Nolte, and I. Bider, Proceedings of the 5th International Workshop on Socio-Technical Perspective in IS Development (STPIS 2019), CEUR Workshop Proceedings, 2019.

[6] S. Kowalski, P. Bednar, and I. Bider, Proceedings of the 4th International Workshop on Socio-Technical Perspective in IS Development (STPIS 2018), CEUR Workshop Proceedings, 2018.

[7] S. Kowalski, P. Bednar, and I. Bider, Proceedings of the 3rd International Workshop on Socio-Technical Perspective in IS Development (STPIS 2017), CEUR Workshop Proceedings, 2017.

[8] S. Kowalski, P. Bednar, and I. Bider, Proceedings of the 2nd International Workshop on Socio-Technical Perspective in IS Development (STPIS 2016), CEUR Workshop Proceedings, 2016.

[9] S. Kowalski, P. Bednar, and I. Bider, Proceedings of the 1st International Workshop on Socio-Technical Perspective in IS Development (STPIS 2015), CEUR Workshop Proceedings, 2015. 